\title{
The Changes in Cameroon's Public Television in the Advent of Digital Switchover: The Impact of Technological Innovation on Audio-Visual Public Policies
}

\author{
François Wakata Bolvine \\ University of Yaoundé 2, Advanced Scholl of Mass Communication, Yaoundé, Cameroon \\ Email: francoiswakata@yahoo.fr
}

How to cite this paper: Wakata Bolvine, F. (2017). The Changes in Cameroon's Public Television in the Advent of Digital Switchover: The Impact of Technological Innovation on Audio-Visual Public Policies. Advances in Journalism and Communication, 5, 1-22.

https://doi.org/10.4236/ajc.2017.51001

Received: December 13, 2016

Accepted: February 12, 2017

Published: February 15, 2017

Copyright $\odot 2017$ by author and Scientific Research Publishing Inc. This work is licensed under the Creative Commons Attribution International License (CC BY 4.0).

http://creativecommons.org/licenses/by/4.0/

\begin{abstract}
Technological innovation strongly impacts the lives of citizens as a whole and is followed by serious consequences on national public policies and on the sector directly concerned. The dynamics of change in the national audiovisual landscape with the public service television engaged in the digital switch-over process is indeed the core of this study. It reveals how innovation has impelled policy-makers to develop a comprehensive strategy, leading to objectives and decisions to completely reshape the national audio-visual landscape with regard to legal, institutional, infrastructural, economic and cultural aspects; and, specifically, public television in its organization, functioning, mission as well as in its uses.
\end{abstract}

\section{Keywords}

Switch-Over, Technological Innovation, Broadcasting, Public Policies, Public Television, Contents

\section{Introduction}

As a major tool in the production of meaning in daily mediation imposed on producers and consumers of its services, television has quickly established itself as a pillar of contemporary culture during the last century. It supersedes all other cultural forms, for which it is the gateway to the audience as an all-encompassing media, disseminating information, entertainment in all its forms, social debate, etc. Largely viewed as a customer medium, television is a new form of participatory culture which is taken over by the audience to bring life to contents, give them life in verbal exchange and the creativity of a meaning co-construction 
relationship using fictions, games as well as talk-shows (Maigret, 2007).

This vision which is based on the ownership theory is in sharp contrast to Marxist analyses and the theory of mass culture so dear to the Frankfurt School that fit this relationship in a confrontational relationship where content producers are driven by a desire to dominate, and which include public authorities (is television not, according to Louis Althusser (1976), an ideological tool for the State?) and producers of wealth, holders of assets, eager to organise society to their advantage, mass media being managed like industries, constantly appealing due to the fact that they

"make you feel better, entertain you, make you dream and hope. The stereotypes they convey water down the complexity of the world and are pleasing by their reassuring monotony. Role models they offer are just ridiculous distractions, some ways to remain locked in an endless state of passivity. Consequently, gambling makes you imagine that your personal distress will soon come to an end" (Maigret, 2007).

Its importance has even become so invasive that it unites especially the national community, $96 \%$ of households with a TV set and its contents coming as the second topic of discussion in companies (after work) and in school (Maigret, 2007). Historically, after being the only masters since its inception with public funding, the government has gradually made way for private investment in television by dismantling the monopolistic positions it had itself built. But by fearing to see the power of the purse (where only catch-all and lucrative programmes with poor contents could prevail) taking over political domination, the authorities have established as rule the principle of maintaining a minimum ratio of so-called public service television channels (Maigret, 2007) with the intention to meet the expectations of a wider public. That is television, though open to the market economy by attracting advertisement-except the Anglo-Saxon model represented by BBC-, should be ready to "lose" revenue by offering "no interest" contents for advertisers but expressing cultural values. This thus entails a stricter definition of its missions (information, education of the masses, entertainment, promotion of national cohesion, etc.). For example, the French public service television which is supposed to meet the expectations of all viewers, not only by being able to entertain, but also by allowing a greater number to be qualitatively fed with more demanding programmes and satisfying the political ambition of shaping the national cultural identity (Campet, Cavada, \& Elkabach, 1994).

Technologically, television operated in an analogue broadcasting system where each frequency could broadcast only a single TV channel until developments in ICTs (signal compression) and scarcity of telecommunication frequencies, increasingly sought after by mobile telephone multinationals and the Internet, did put pressure on States, forced by the International Telecommunication Union (ITU) to switch to a technology that further broadens the broadcasting spectrum, releasing frequency packages. Incidentally, the audio-visual media landscape got new television channels to satisfy an increasingly diversified audi- 
ence and closely targeted expectations through competitiveness. Henceforth, each Member State is obliged to include the Geneva 2006 international Accords (GE06), adopted within the framework of the technological component of the United Nations Organisation (UN) that is ITU. International commitment inspired by technological advances has therefore influenced policy development at the international level (ITU) and, subsequently, is included in the political agenda of countries and obliges each country, depending on the geographical region it belongs to, to respect a specific timing for the switch-over to Digital Terrestrial Television (DTT).

If the trend that began in 2006 is generally under control in developed Western countries, Africa was authorised to achieve it on 17 June 2015, latest. Now, how has Cameroon factored in this new international requirement in its political agenda? How is this technological innovation, coupled with international political requirements structure the development of public policies as concerns the audio-visual sector with a clear impact on public television? It should be noted that this concept refers, on the one hand, to the science of the State in action (Muller, 2011) and, on the other, to the actions of an authority vested with public power and government legitimacy in a specific area of the society or territory (Boussaguet, Jacquot, \& Ravinet, 2010). What consequences will this technological innovation have on the morphological structure and functioning of the organisation? Will the traditional missions of the Cameroon public television (CRTV) withstand the invasion of this innovation and its attendant constraints and uncertainties? All the more because it is faced with many dangers, including the obsolete nature of the technical tool, the lack of incentive of a significant portion of managers and staff of the company, the stagnant nature of its programme offer, geared towards satisfying the institutional information and decision-makers (The ad-hoc committee charged with the restructuring of CRTV, 2012) of which, in final analysis, it reflects?

As we observe the manifestation of public action and the internal strategy developed by the organisational techno-structure, we can infer that technological changes strongly impact on national political agendas, by incorporating in these agendas problems to be solved as concerns the issue of the survival of public television faced with the increased capacity of the media landscape to significantly increase television offer. This possibility seems to be potentially risky for public television that is already faced with a dwindling audience since the liberalization of the audio-visual landscape, while there is still, in terms of its public service missions, the constraint of broadcasting programmes that are not necessarily attractive, contrary to private channels with less cumbersome organisational and bolder structure in attracting the interest of a fragmented and extrovert audience (Bilé, 2015).

This study examines the impact of innovation on this sociological tool which is television, in that it changes its morphology, status, internal practices and purpose as a cultural industry in its interaction to co-produce content for the audience which is the major consumer of "mass culture". Ultimately, it is a ques- 
tion of highlighting the logic at work that impacts on the public television, transforming it in the digital switch-over process. Literature review (general texts, laws and regulations, study reports, etc.) and diachronic analysis requires drawing up a picture of profound changes in the digital age; this requires referring at times to some historical landmarks of this change process (Charon, 2011). Thus, after analysing the technological and infrastructural constraints on public television, the study will address the challenges of content production within the new environment, reviewing changes in the legal and institutional framework, the financing of the audio-visual sector and the development of human resources in the digital environment.

\section{Technological and Infrastructure Constraints}

This entails examining how the technological evolution coupled with international political decision have compelled public authorities to rethink the social mission of television, its internal practices as an economic techno-structure and political and strategic order shaping its inclusion into the national audio-visual media landscape. This requires reviewing public service principles, particularly that of DTT and its implications and, ultimately, its repercussions on the structure of public television.

\subsection{Public Service Principles of Television}

As a debated concept, the public service television should be designed, in a context where, because of its vulnerabilities (increased competition from the private sector, dwindling advertisement revenue, reduction of its missions etc.), it is increasingly imitating the private sector, by minimising notably risks taken in programmes. Many reports and studies have been made public in France and Britain, questioning its missions, funding and management and positing that the public service cannot cope with the rapid technological changes and behaviours of televiewers But as all-citizens television, attention paid to the audience must be, as far as it is concerned, more of a public concern than commercial performance its main concern should be performing its missions defined by public authorities. Objectively, these missions are of general interest, while considering:

"the most diverse social trends in the artistic, philosophical, religious or political fields, contributing to the information and education of citizens, the promotion of heritage as regional or foreign cultures on the national territory, the expression of differences as to social cohesion" (Campet, Cavada, \& Elkabach, 1994).

In fact, television seems mainly to be a powerful medium for public authorities-populations interaction in order to garner the support and mobilization of the latter around government programmes. This guarantees to the former an audible and loud voice to send their messages (Bandolo, 1977; Minlo, 2013) through and more recently to counter the expansion of national private radio-television stations and the availability of satellite channels with potentially risky contents for their strategies to hold on to power. The resulting audio-visual 
policy thus structures upstream these missions around the following areas: source of information for the public, recreational and entertainment slots, teaching and education tools to understand the world and prevent crisis, privileged place of learning and exercising citizenship, a window to the world (The ad-hoc committee charged with the restructuring of CRTV, 2012). Under these conditions, its role in the social field is beyond commercial constraints since it is primarily financed by the State and focussed on meeting the expectations of a mixed audience, the diversity of which further complicates action. Indeed, it is by getting a wider audience interested and knowing how to entertain that it allows the largest number to follow more demanding programmes that shape cultural identity (Campet, Cavada, \& Elkabach, 1994). This leads it to offer programmes that are, by definition unprofitable and neglected by its private competitors who do not take into consideration whole segments of the national population.

But the advent of DTT in an environment characterized by fierce competition between programme editors and the instability of viewers, necessarily require a reform of the public audio-visual media sector, as this technology inevitably leads to the weakening of its position as the traditional operator, greatly increasing the exposure of the population to contents different from those it offers. CRTV is now at a crossroads: under these conditions, how to increase and improve programme offer while maintaining its public service mission, a millstone around its neck? It is therefore necessary and urgent to question the DTT dialectic-audio-visual public service, in order to highlight changes that structure their interaction on a daily basis.

\subsection{The Rationale behind the Digital Terrestrial Television Switch-Over}

DTT markers on national audio-visual policy and, particularly on public television, a reflection of the international commitment to switch-over in public policy included in the political agenda of Cameroon are of three categories: Technological, economic and strategic.

\subsubsection{Technological Markers}

The Cameroon public television officially launched colour programmes on 23 December 1985, twenty-five years after most African countries, trail-blazers of black and white venture in the wake of their independence. The first country to set up a television channel in this African region is Congo Brazzaville. From 1960 to 1983, all sub-Saharan African countries, except Cameroon and Rwanda, already had a television station (Dioh, 2009). At the start of the switch-over to DTT, the entire broadcasting equipment of the public channel nationwide using 38 broadcasting centres operating in analogue mode and production equipment, outdated after almost 30 years of service, have begun being digitalised. CRTV was the only operator in the Cameroonian audio-visual media landscape, till the 90s with the liberalization of the audio-visual sector, which will favour, firstly, the arrival and proliferation of private television channels, thanks to the Decree 
of 3 April 2000 and then, a phenomenon that will revolutionize the African audio-visual media landscape, namely, cable television with hundreds of television channels dumped on the continent via satellite.

However, the mode of organizational functioning of national channels is still governed by the principle of concentration of broadcasting and production activities, that is, structural verticality with no flexibility, the same operator controlling the entire chain from the production to the broadcasting of contents. Especially as the broadcasting of programmes is in analogue mode, a technology that has many flaws: in addition to being highly energy-and frequency resources consuming, analogue broadcasting, because of its technical limitations-broadcasting of a single programme on a single frequency-does not meet the increasing demands of stakeholders of the audio-visual landscape, whose services are increasingly using multimedia and mobile or interactive applications. On the contrary, digital broadcasting, thanks to digitalisation and compression techniques, proposes multiple programme broadcasting on a single frequency.

Departing from analogue television organisation, DTT inevitably allows for a separation of production activities from those of broadcasting. Moreover, the latter easily fits in multiplexing activities (uploading of various TV programmes in the same transmission frequency), clearly promoting the sharing of some functions of the channel in television. Infrastructure sharing refers to the operation on the same sites of several different operators under contract. The most visible sharing experience is that of "high points" or the same transmission/ broadcasting sites. Based on this, the so-called "virtual" networks can be built, leading to a significant improvement of service offer. In addition, multiplexing allows the deployment, on the frequencies released, of innovative services such as $3 \mathrm{G}, 4 \mathrm{G}$, e-commerce, interactivity, e-banking, e-learning, including the specialisation of actors, each in a specific trade, ICTs network convergence (common support of transmission) and the versatility of terminals. This device, in its complexity, seems to be a catalyst for the diversification of service offer, with an opportunity for increased competition within each new segment of the operational television chain. This makes it possible to receive indiscriminately images, sounds, data and Internet, on terminals such as TV, mobile phone, computer, etc. and immediately changes the mode and place of watching television.

\subsubsection{Economic Markers}

The transition to digital broadcasting is an opportunity to optimize the exploitation of terrestrial natural resource, on the one hand, and an opportunity for States and economic operators respectively to derive substantial financial resources from the sale of "digital dividend" - the "golden frequencies" released after the digital switch-over and sought after by telecommunication operatorscollecting taxes from the activity of the many operators of the sector and operationalising e-commerce and e-banking, on the other hand. In 2000, Germany sold the first dividend for 50 billion Euros; France at 2 billion Euros in 2014 for the second dividend; Nigeria at CFA francs 100 billion in 2015. According to a study by the consultancy firm Analysys Mason/FTPA/Osiris Intelligence Straté- 
gique (2014), the Cameroon government consultant for the legal, economic, financial and content-related aspects within the framework of the DTT switchover process, digital switch-over may help to improve by about $25 \%$ the contribution of the telecoms, media and ICT sector to the Cameroon Gross Domestic Product (GDP). With the development of these new services, digitalisation seems a key element in terms of resources and economic growth. Reason why the State as regulator, taking into account the market value of goods and services, is trying to strike an economic balance, not always easy to achieve, between producers and customers-consumers. Indeed, this entails establishing a link between the activity of a consumer good producer and its impact on the physical and human environment.

In the case of digital switchover, the State, by putting in place a new institutional and regulatory environment, makes sure that this macroeconomic balance is respected at the end of the process, to avoid tipping the pinlever toward one or the other end, that is, either solely to the advantage of producers, or to the advantage of consumers. The benchmark of the Cameroonian public service audio-visual media reveals a mixed profile, with a predominance of the audio-visual tax in financing the public television whose annual contribution is about CFA francs 12 billion; and the invasion of the sector by cable operators (operating illegally both from the point of view of the law and international editors they rebroadcast programmes without any financial compensation) who benefit from the bulk of resources of the sector. According to the Consultancy Analysys Mason/FTPA/Osiris Intelligence Stratégique (2014), the annual turnover of cable distribution in Cameroon is about CFA Francs 48 billion. The narrow nature of the advertising market due to the combined effects of a weak industrial base, the inability of television to broadcast nationwide and the lack of quality local programmes, does not either allow to diversify sources of funding of the public television. Another salient fact is the multitude of editors operating in the sector, mostly illegally and their revenue, which is difficult to quantify, do not contribute to the national economy. Finally, the pool of television receivers, handicapped by a fragmented and unevenly distributed power across the national territory remains fairly low, especially in rural areas.

DTT technology, by encouraging respectively the arrival of new operators, a new regulation and by introducing new uses of television, plays an important role in the new funding of public audio-visual media, by reducing its over dependence on audio-visual tax. New funding opportunities provided by the regulation in force mainly come from licenses, concessions, approvals and accreditations revenues granted to operators, renewal fees, money accruing from sanctions, taxes on audio-visual service distributors and on mobile broadband operators, the benefits from the sharing of broadcasting equipment, the $2.5 \%$ annual contribution from the turnover paid by all operators for the development of the sector, and monetization of digital dividend. In addition Analysys Mason/FTPA/Osiris Intelligence Stratégique (2014), asserts that digital switch-over may help to improve by about $25 \%$ the contribution of the telecoms, media and ICT sector to the Gross Domestic Product (GDP) of the State. The resources 
listed hereunder may be around CFA francs 70 to 100 billion.)

Resources derived from new services and taxes accruing there from will help to boost the sector's contribution to the State budget, especially video on demand, marketing of set-top-boxes and reception kits or catch up TV, etc. All these resources paid into the State coffers, will enable it to have sufficient resources that can be used to finance the public audio-visual media, which requires significant financial resources, all the more as it has just been organised into six (6) separate entities.

\subsubsection{Political and Strategic Markers}

By getting into States political agenda, DTT calls for the logic of international cooperation jointly with the levers of national policy and societal implications. At the strategic level, digital switch-over emphasises the need for Government to rigorously and sparingly manage frequencies, scarce resources that are used in very sensitive areas such as security, civil, aerospace and military and frequency coordination at borders. This obliges States, on the one hand, to comply with the Accords and Regulations of the International Telecommunication Union (ITU) in establishing national DTT networks and other telecommunication service networks and, also to implement management policies that maximize the overall benefit of this resource for the advantage of the entire society. This benefit extends to social values such as peace, national unity, education for all, cultural identity, etc.

Guaranteeing benefits to all social components necessarily requires the State to ensure fair competition among operators, so as not to focus and confiscate the spectrum in space and time in the hands of dominant operators, by encouraging particularly each of them to offer the best services at affordable costs. As value is due to scarcity, States avoid putting to competition the entire spectrum for a given use at the same time. This allows to increase the cost of transfer and to admit new operators and innovative technologies after a deferred time. The responsibility of States is even greater in that, by encouraging infrastructure sharing, they promote the presence of several operators under contract on the same sites. The sharing of infrastructure by all spectrum users generates earnings and returns on investment. Nevertheless, this brings in its wake some constraints on operators-beneficiaries, considering particularly the digital divide between cities and countrysides (coverage and quality of service obligation along with compensation). Yet, operators tend to invest in cities where the majority of their customers are, abandoning countrysides, thinly populated, where investment costs/operating costs ratios are almost not profitable or even negative. But benefits for the society are the same in these areas.

\subsection{Impacts on the Structure of the Public Television}

The integration of TNT in television organization brings in variations in the understanding of the concept of public service audio-visual. Technological innovation causes a review of the issue of public television that fits into sectors in accordance with the new dispensations of its operating mode. Until now CRTV 
that was bound to encompass the whole chain of activities from production to signal reception at the end, is engaged in a process of separating and specializing the management of the production, transmission, multiplexing, broadcasting and reception segments which are now operated by many independent actors. This means either a reform of its social object whose values and practices are expected to adapt to the new technological environment. Hence, a new managerial approach to this audio-visual complex where the public television should now focus on the production of quality contents (necessary to maintain an audience highly sought after), but also committed to preserve the cultural identity in the face the influx of foreign channels. It is incumbent on other actors to be involved in hitherto missions: provision of radio and television signal, territorial coverage by reducing poor reception areas, fairness in the treatment of actors, quality and continuity of service, etc.

Such specialization provides several advantages. It differentiates the public audio-visual structure currently built around a gigantic and centralized corporation and also leads to a fair allocation of specific resources to each media (public radio and television) for its missions, provided radio is separated from television. Or the balance between the two media is restored, in contrast to the current situation where the radio is neglected in the public audio-visual sector. It also focusses on the core objective of an audio-visual editor, namely the production of accessible and attractive programmes to help increase its audience and market share. Finally, it confirms the mixed mode of financing public broadcasting backed by three pillars: audio-visual tax, State subsidies and advertising revenue. The inevitable devolution of broadcasting activities to a third entity will close the process of separating public television activities brought about by digital technology (The ad-hoc committee charged with the restructuring of CRTV, 2012).

\section{Improvement of the Legal and Regulatory Framework}

The transition to digital television, particularly because of the specificities of this technology, triggers profound changes in the organizational and functional framework of the public television operator, given the necessary attendant developments in the audio-visual landscape.

\subsection{Digital Broadcasting Technology Constraints}

The digital television environment comprises the production of goods and services (fixed and mobile telephone, audio-visual services, data) of the telecommunications sector for consumers and provided by a variety of operators: telephone operators, Internet service providers, radio and TV programmes editors. It introduces a new technology requirement that immensely impacts on the legal and institutional framework for public television. This is clearly demonstrated through the exchange areas on the construction of communication links between various operators to the device, raising the issue of fair access of all to such a hub. Another essential marker of the new environment is the arrival of multiplexing/broadcasting operators of audio-visual signals, infrastructure own- 
ers and located at the convergent area of an organized network of service editors, who no longer have to worry about the difficult question of broadcasting their programmes.

Instantly, there is the acute problem of regulation from two main perspectives. First, issues related to the technical quality of messages in relation to user comfort and safety in the transmission of such messages. This concerns primarily the technical standards to be respected, firstly, in terms of electrical signals generated by messages (role of the Telecommunications Regulatory Agency-ART), and, secondly, technically securing these signals (role of ANTIC in collaboration with ART), given the different transmission media through which signals transit. Secondly, issues relating to the meaning given to messages sent to users, while respecting their fundamental rights of access to information, while preserving privacy (roles of NCC and ANTIC).

\subsection{Audio-Visual Legal Framework}

As we enter the digital area, the system of electronic communications in Cameroon hinges on the principle of separation of the telecommunication and ICT component from the audio-visual component. Specifically, and as far as regulation is concerned, the Ministry in charge of Post and Telecommunications is in responsible for the drafting of the instruments to govern telecommunications and ICT, whereas the Ministry in charge of communication drafts those on audio-visual communication. The regulation of the two sub-sectors is keeping the pace: the Telecommunications Regulatory Agency (ART), regulates, controls and monitors the activities of electronic communications operators as well as allocates radio frequency. At the national level, the inter-ministerial committee in charge of allocating frequency bands (CIABAF) is charged with the harmonising of the use of radio-frequencies and the National Agency for Information and Communications Technology (ANTIC) regulates, controls and monitors security activities of electronic communications networks and information systems. It is the duty of the National Communication Council (NCC) to regulate the audio-visual sector whereas the institutional body in charge of regulation (ministry in charge of communication) allocates frequencies, which also acts as an administrative police with powers to look into the activities of the regulator. They are increasingly questioned, as the regulator feels the will of public authorities to reduce its power.

More globally, Law No.90/052 of 19 December 1990 on the freedom of mass communication establishes the framework for the exercise of the freedom of expression enshrined in the Constitution. It replaces Law No.66/LF/18 of 21 December 1966 on the press whose anti-freedom nature was increasingly challenged given the socio-political environment of the $90 \mathrm{~s}$, that was open to the plurality of expressions. This law has significantly contributed to the creation of many newspapers and the development of audio-visual communication enterprises. With this law and Decree No 2000/058/PM of 3 April 2000 to lay down the terms and conditions for the setting up and operating of private audio-visual 
communication companies, the audio-visual landscape saw the setting up of more than a dozen television channels. Most are operating illegally or under administrative tolerance; this exempt them from abiding by some obligations. Practically, the audio-visual sector in Cameroon is governed by a wide range of texts that come in to enforce or amend the Law of 1990, without prejudice to the general instruments or relating to the electronic communication sector. General texts on mass communication and those governing the electronic communications sector are enforced on the audio-visual sector, given the technology complementarity and convergence ushered in by the new digital environment. The recent changes in the telecommunications and ICT sector undergoing a wide range revolution, necessarily impact on the functioning of the public channel, particularly through the opportunities provided by the new regulation governing audio-visual activities and the aforementioned electronic communications sector.

More specifically, the Law of 17 December 1987 to create CRTV provides for the merging, on the one hand, of Radiodiffusion du Cameroun (Cameroon Broadcasting Corporation), a network of stations broadcasting throughout the country placed under a department of the former Ministry of Information and Culture and, on the other, the Cameroon Broadcasting House (Cameroon television-CTV) created by a Presidential order of 26 April 1986. Decree No.88/128 of 25 January 1988 set its organization and functioning as a public industrial and commercial establishment placed under the technical supervision of the Ministry of Communication and the financial supervision of the Minister of Finance. In accordance with the Law of 22 December 1999 on the General Status of public institutions and public and para-public sector companies, adopted within the framework of the Organization for the Harmonization of Business Law in Africa (OHADA), these establishments are henceforth State-owned corporations. This organisational model has prevailed till date, giving room only to minor changes featuring in the various organisational charts adopted over the years (The ad-hoc Committee charged with the restructuring of CRTV, 2012).

Nevertheless, the global context in which public television operates should be competitive, for since 1990, that is, 3 (three) years after CRTV was created, Cameroon adopted a new legal framework promoting the liberalization of the audio-visual sector. This has had as immediate consequence the creation of several private audio-visual communication companies and the putting of CRTV in a competitive environment in which its basic texts, adopted in an environment marked by the absence of private operators in the audio-visual sector, did not prepare it for.

\subsection{Legal and Institutional Changes in the Public Television}

New technology requirement imposes the adaptation of the Cameroonian system of audio-visual regulation, as well as the end-to-end digitalisation of the various components of the chain to create an added value in the telecommunications and ICTs sector have led to a convergent digital economy. The concept of 
convergence refers to the design of a technological framework with no separation between telecommunications, ICT and the audio-visual media. This has made States to review the institutional and legal frameworks governing the audio-visual and electronic communications sector, in order to derive utmost advantage from a sector that is on the verge of becoming the backbone of the economic and social development of the population. Considering these changes, Cameroon has established a regulatory framework in anticipation of the arrival of new operators, such as developers of multimedia contents, infrastructure operators, distributors of products and services to customers, etc. Between these producers of wealth are regulatory institutions: ART for related infrastructure and resources, ANTIC and the National Communication Council for contents. The modelling of the whole industry is predicated on the specialization of trades as mentioned above. That is a world of services providing multimedia contents and a world of infrastructure conveying these contents. Thus organized, the converging points of these data flows, such as IXPs (Internet Exchange Points), the landing points of the cables and multiplexing centres of digital terrestrial television become key links in both reducing the costs of telecommunication services, and ensuring State security.

The effects for public television in a telecoms-ICT and audio-visual sector henceforth unified, lead to a rapid change in its organisational framework as provided for by the April 2015 Law governing audio-visual activities. The redefining of the institutional framework is in keeping with the creation, based on CRTV, of several operators specialized each in a segment of trade generated by DTT, including broadcasting and production (which public authorities intend to separate into two entities: TV and radio), without losing sight of enhancing the regulation and archiving of contents to preserve the audio-visual cultural heritage. Against this background, the multiplexing and broadcasting operator as per the law, is responsible for ensuring, in the public interest, the functions of multiplexing and the operations needed for transmission and broadcasting to the public of programmes of audio-visual service editors via terrestrial mode, optic fibre, satellite or any other technical means. As a technical structure, it is required to comply with broadcasting quotas, as well as the requirements for specialization and respect for texts and other standards. As for the public editor, it continues to ensure, in the public interest, Government policy in the television and radio sectors. As such, through its programmes, it is obliged to meet the needs of the populations in terms of news, culture, education and entertainment.

The already existing audio-visual regulatory body should henceforth freely discharge its duties and have the required material, financial and human resources; The facility for the storage and conservation of audio-visual contents, that is also set up by law, collects, catalogues, archives and restores, for collective memory, audio-visual contents, so as to make them accessible to all, for educational, cultural and research purposes, under certain conditions. Lastly, though not resulting from the splitting of CRTV, the audio-visual sector's development fund established by law, meets the need to support audio-visual projects and programmes, especially activities aimed at promoting a competitive national 
sector.

The audio-visual sector and especially, television is constantly changing to adapt to DTT requirements. Still to be effective is the split, which, by specializing more trades, raises the question of the necessary restructuring of the staff.

\section{Socio-Professional Changes}

As a major user of all kinds of technical and artistic trades, the public television, in its vision of the future, can no longer be contented with an expertise inconsistent with DTT innovative technologies, especially as regards the staff assigned to broadcasting. Their training in the specialities of the new dispensation is of essence, since the current professional profiles seem clearly obsolete.

\subsection{Training Requirement}

The socio-professional changes inherent to DTT in general and the digital television public service in particular, are the same as the above mentioned technological changes. This issue is central to the digital economy environment considering the new trades, new production modes and adjustments of technical skills it implies. The stake is such that this issue was a central focus of a global forum on capacity and skills building in South Africa in 2012, in prelude of which the Director of the ITU Telecommunication Development Bureau (BDT) said:

"This year, the Forum is held under the theme 'Digital Inclusion: Preparing human capital for a knowledge economy'. The deadline for transition to digital terrestrial television broadcasting, set for 17 June 2015 for most countries, is fast approaching. The period between now and then is crucial to transform the skills existing in the field of analogue technology into digital skills at different levels within organizations and from one society to another, in order to fully take advantage of the potentials of the digital age".

The "human resources development" component has, naturally, the mission to contribute, within the DTT context, to upgrade, specialize and qualify the existing human capital in each country, to optimize all development niches offered by television in the digital ecosystem. However, the scope of these changes depends on the baseline situation in each country and the gap of volumes to be filled, in terms of the quantity and quality of human resources for an optimal functioning of all the structures in the value-chain of production-broadcastingmultiplexing-aggregation-regulation.

In developed countries, DTT falls within a context where the quality and quantity of skills are already guaranteed to optimize the contribution of this technological advancement in the national economy as a whole. But in the case of least developed countries in general and Cameroon in particular, the baseline situation is relatively more complex, given the diversity of trades affected by this change. There are broadcasting engineers who master the analogue technology. But their number is steadily decreasing, many having worked for over 30 years in public television. As they go on retirement, most go private thanks to the lib- 
eralization of the audio-visual sector. There are few young engineers graduating from universities and higher institutes. They underwent a general training on DTT technology theory. However, there are increasingly university and professional training structures, both public and private as the foundations for DTT training. Their technical platforms and teaching curricula however require some adjustments more attuned to digital television.

What remains to be done is to establish the correlation with equipment and technology used effectively for DTT. Some of the executives from the technical and artistic sectors are largely poorly trained and with low exposure to the industrial vision of content production. They operate in an environment that is still fragmented, separating internal production of television channels from the so-called independent production. The national consultation on contents and the building of the first DTT bouquet, organised in Yaoundé from 2 to 5 August 2015, under the auspices of the Cameroon Digital Television Project (CAMDTV), confirmed both the weak structure of the production sector and the lack of cooperation between channels while independent producers lack expertise and resources. The series of opportunities to be valourised is as complete as consistent.

The digitalisation process is primarily a technological innovation, human resources will be upgraded or developed as a matter of priority in the technical and technological segments of the broadcasting, production and audio-visual transmission networks. The trades concerned are related to edition, content aggregation, distribution, provision (broadcasting) and, more generally, to traffic and access to television, etc. Beneficiaries, from both companies and in liberal professions will then be able to perform a wide range of trades, created by the multifaceted activity of the sector.

\subsection{Lack of DTT Skills}

At inception, national television staff came from broadcasting, the forerunner media agent of the State (Radio Cameroun), and from some administrative services including the Ministry of Information and Culture, the Diaspora, the private sector and institutions of higher learning, like the National School of Posts and Telecommunications and the National Advanced School of Engineering. Thirty years later, the issue of the development of various human capacities proves essential, particularly with regard to the implementation of the DTT process. Especially that, in its Strategy Document of Cameroon for the analogue to digital switch-over (DSC-MN), the Government took the option to place public television at the centre of the DTT system by establishing the CRTV broadcasting network as the starting point of the national DTT.

The most recent data on the general situation of CRTV human resources (Report of the sub-committee charged with the counting and auditing of CRTV salaries, 2010; Report on the evaluation of CRTV human resources set up by the Board of Director, 2010.) shows a diversity of staff profiles, with nonetheless a high number of technical trades (Engineers, technicians and senior technicians, 
technical agents, computer analysts, system designers, designers, cablemen, climbers, light technicians, editors, directors, producers, assistant producers, sound technicians, assistant sound technicians, etc. that is 545 persons.) This category is primarily concerned in the upgrading or training in DTT technology. Moreover, data from successive reports (the ad-hoc committee on the restructuring of CRTV, 2010); the ad hoc Committee charged with the evaluation of CRTV human resources (2010.) reveal different and varied staff workforce and a difficulty to control this number by CRTV itself. Estimates as of 12 November 2010 identify 1667 persons, excluding support staff, temporary staff, freelancers and staff with extension of contract. In addition, the ageing workforce is poorly distributed across all the sites in the corporation, with an acute shortage of staff both in rebroadcasting centres and in the categories of "directors" and technicians in particular. The last recruitment in these sectors dates back to 1988 (the ad-hoc committee charged with evaluating CRTV human resources, 2010). Hence, the need for the public corporation to, on the one hand, recruit younger workers in these categories particularly challenged by DTT and, on the other, to build the capacity of available staff which though requires new skills.

Lastly, possibilities offered by DTT technology, including signal compression allowing broadcasting, on a single frequency of many channels has opened new prospects to the public channel that already, as what obtains in countries that have successfully switched over, to create more specialised channels : all-topic channel, regional news, sports and culture, cinema, music etc. In this respect, the public television entity cannot obviously rely on its current workforce, in all its segments.

\section{Challenge of Content Production}

Television as mass media is involved, through the contents it conveys, in moulding collective consciousness. From this standpoint, contents are of paramount importance, particularly because of their ability to structure the thinking of society by transmitting values and offering to everyone a vision of the world and society (Campet, Cavada, \& Elkabach, 1994). The stake is therefore societal and whatever the mode of transmitting contents considered, it has an impact on the entire society. This information is of greater importance given that a Cameroon Digital Broadcasting Switchover (CAM-DBS, 2011) report revealed that in 2011, 30.71\% of Cameroonian households had a TV set. This further supports the data from the National Institute of Statistics which reveals that there are 6 million TV sets available in Cameroon. But if we consider a lower average of two persons per household, we notice that about 12 million Cameroonians watch television, that is more than half of the population; except in areas not covered or with no electricity. But DTT technology entails new challenges to television, since it offers the possibility to expand its audience by a multiplying effect, due to the simultaneous broadcasting of several channels to varied audiences, closely targeted as in the marketing world. For a long time as single operator, the public television witnessed the arrival, in the late 90s and early 2000s, of competitors 
who have contributed to the diversification of programme offer, without significantly improving it, quantitatively or qualitatively. With the advent of DTT, content production has become a major challenge, especially as the starting situation is not optimistic, local production being obviously at a budding stage on the one hand, and Cameroonians displaying an extrovert audience with preference for entertainment programmes, on the other. The aforementioned status report revealed that, by order of priority, Cameroonians watch movies, TV series, news, sports, cultural programmes, etc.

\subsection{General Situation of Contents in Public Audio-Visual}

Granted, in principle, the advent of DTT brings no fundamental transformation in the design process of content production. However, it brings in significant challenges to overcome, from a baseline situation, which over the years has gradually declined. In fact, for close to twenty years, public television has had monopoly in the broadcasting of television programmes in Cameroon. Even today, despite the presence of some thirty private channels, public television still has the best terrestrial broadcasting network (CAM-DBS, 2012). This advantage makes it the medium that provides the greatest territory coverage of the $\left(65^{\circ} \%^{\circ}\right)$ existing analogue network (Analysys Mason/FTPA/Osiris Intelligence Stratégique, 2014). But a diachronic analysis of contents offered by public television reveals that it has not taken advantage of its dominant position. If the early years were marked by some local productions in the cultural sector (heritage dances, cookery, customs and traditions, history, music, etc.), they were the work of voluntary professionals and actors driven by the fascination of this medium. Cameroonian fictions as TV movies, series and serials have been produced at the same time, with great success on an audience which was discovering television. We can refer among others to: "le procès de Wabo Deffo", "le retraité", "Ntaphil", TV series "le Procès" and "silence, on joue"; "l'orphelin", "le débrouillard", etc. But over the years, this impetus died down to give way to flow programmes, less financially demanding. Internal initiatives like the setting up of the integrated production Unit, were not enough to offset the trend, most of the stock programmes coming from abroad whose productions overshadow local productions (Bilé, 2015). Hence this statement by the consultancy firm Analysys Mason/ FTPA/Osiris Intelligence Stratégique (2014):

"The under-representation of Cameroon stock programmes is to be compared to what is observed in several English-speaking countries of the continent, and particularly in neighbouring Nigeria, where a flow of cheap productions rapidly amortised in the domestic market can now be exported...".

This remark should nevertheless be tempered by mentioning that this clearly is a general tendency both nationally (private channels are no better) and internationally. Delphine Ernotte CUNCI, Chair of France Télévisions (2015) indicates that France has set the limit of "independent" production at 5\% to force France Télévisions to order $95 \%$ of its fictions from independent producers. This rule has led to the development of audio-visual production of about 2.300 pro- 
ducers, including about 250 for fiction with a total turnover of about 2.4 billion Euros, according to Analysys Mason/FTPA/Osiris Intelligence Stratégique (2014). Moreover, the general situation produced in 2014 by the Consortium Analysys Mason/FTPA/Osiris Intelligence reveals that the contents of the Cameroonian public television is shown in a very flexible or legible schedule, with few cross-cutting meeting points and with a rather heterogeneous daily distribution. They give pride of place to television newscasts and information magazines, presented on all topics and consisting essentially of "talk shows" and neglecting topics promoting the types of programmes that appeal to the audience and make a difference (Analysys Mason/FTPA/Osiris Intelligence Stratégique, 2014). Inevitably, public television contents show a profound imbalance between flow and stock programmes. The latter, by far the majority, are from two major sources: foreign TV series and serials (South American, Indian, French, English) and movies, documentaries, recordings of shows, live shows, offered free of charge by CFI data bank of programmes, which are not necessarily useful to the receiving country (Mattelart, 2015).

This tendency for more foreign programmes is not going to be reversed soon as production expenses at CRTV are proving insufficient to support so-called in-house as well as so-called independent production. In-house production (excluding staff costs) amounts for example to CFA francs 1.6 billion, whereas independent production (expenses on the purchasing of contents) stands at CFA francs 700 million (Analysys Mason/FTPA/Osiris Intelligence Stratégique, 2014). Hence, an obvious under-funding of local production as briefly mentioned above.

The limiting factors to production of competitive contents by public television include: extrovert contents; low domestic production; predominance of flow over stock programmes; sudden introduction of competition from foreign channels broadcast by illegal cable operators, all compounded by the underfunding of domestic production and inadequate skills for digital production (Analysys Mason/FTPA/Osiris Intelligence Stratégique, 2014). The question now is to know how the public television, already unable to meet its production obligations with a single channel will be able do it with 6 (six) channels, each with a specific editorial policy, not only to satisfy its audience, but especially to face competition from foreign private channels whose presence will be reinforced with DTT.

\subsection{Challenges of Independent Production}

The issue of DTT, with its attendant opportunities, constraints and organizational uncertainties has forced public television, under State control to implement a series of measures to address the challenges of content production in a context where policy-makers are willing to support and promote, using the audio-visual sector, national creation, to showcase the daily life of Cameroonians and to promote domestic culture and wisdom. The State and CRTV have thus respectively taken a series of measures aimed at no more no less, to ensure the 
survival of the public television in a context where competition from national and international private channels covering the country through all channels is a real danger.

\subsubsection{Government Measures}

As the main stakeholder of public broadcasting, the State has decided to create an environment likely to promote the efficiency of the strategies adopted internally by the management of the public broadcaster. As such, in its mission to structure the society, it developed through CAM-DTV, a national switch-over strategy that has come up with the profile of the future national audio-visual media landscape, a system at the centre of which stands firmly the public television whose broadcasting infrastructure is the basis for the building of the DTT network. This strategy was followed by the establishment of an appropriate legal framework governing audio-visual activities in the new environment and promoting the convergence of telecommunications and ICT, all contributing to the development of the audio-visual sector.

The law governing audio-visual activities, enacted in April 2015, in addition to the advances mentioned above, established the public funding of the audio-visual sector by instituting, on the one hand, an audio-visual development fund to support the content production policy which will provide additional resources to support dependent production within channels and independent production devoid of means and, on the other, a centre for processing and archiving audio-visual contents, thus anticipating the start of a policy for the industrialization of content production. Various taxes are also provided, applicable to the activities of cable distributors and other audio-visual service providers, to operators of broadband mobile telephone as well as levies on import duties and license fees for telecommunications and audio-visual operators, etc.) and the turnover of telecommunications operators called upon to operate in the frequency bands released by terrestrial broadcasting. These initiatives aimed at funding production and industrialization, are fundamentally necessary for the implementation of a far-reaching content production industrialization policy, backed by the establishing of production quotas and local production broadcasting. Industrialization allows considering large-scale production of national audio-visual content, for the creation of a critical mass capable of supplying programmes to the domestic or even sub-regional market, where public and private channels would purchase programmes, as stated by the Consultancy firm Analysys Mason/ FTPA/Osiris Intelligence Stratégique (2014):

“(...) One can think of mechanisms relating to the management of the broadcasting rights of heritage works or real market of programmes allowing channels to purchase Cameroonian productions with better information on the programmes available.

However this intention would have been just wishful thinking if it were not backed by a genuine professionalisation of the audio-visual production sector, through the training of seasoned professionals and sufficiently skilful to sustain the demand of the national market for programmes. It is in this spirit that the 
government, on the one hand, organized in October 2015, a training session for thirty (30) officials in charge of production and programmes in Cameroonian public and private channels and on the other, embarked on discussions with Brazilian authorities, which in 2015 culminated in the drafting of a cooperation agreement protocol to support the production of contents and the training of production professionals.

\subsubsection{Measures Inherent to Public Television}

The challenges of the public television, in terms of contents, are many and varied. Since DTT entails the principle of multiplication of broadcasting channels, the problem of providing them quality programmes is thus a key issue in the switch-over process, in reducing the over-dependence of the Cameroon audio-visual on foreign programmes as well as the need to win back the audience being a priority. In this perspective, public television is intended to ensure the creation of heritage works and to become the tool for a strong presence of Cameroonian programmes produced by Cameroonians and intended, primarily, to the Cameroonian audience while being exportable. Two consultations aimed at identifying the expectations of Cameroonians from television programmes have just been organized to this effect in Cameroon, respectively by CAM-DTV and CRTV (CAM-DTV intended, on the one hand, to collect proposals on the constitution of the first free bouquet of 30 (thirty) national channels and, on the other, the major topics likely to serve as matrix for the production of local attractive and competitive contents. It was followed in October 2015 by the consultation on public television programmes, with the objective to build the contents of its 6 channels).

Although domestic production, due to the constraints it entails, is not able by itself to bridge the gap, a number of measures have been taken by public television to ensure a minimum presence Cameroonian content on its channels. But the challenge is enormous, because to succeed, the analogue production must be tripled, certainly taking into account public needs, but only up to a certain extent, public service mission requiring public television to be more daring, to go beyond the market, without being contented to follow the audience, but offering innovative programmes, difficult topics; in other words, by getting out of the audience logic to embrace a stronger demand in its programming, as proposed by Balle (2007).

The ability to establish cooperation ties with foreign countries mentioned above and the expected financial fallouts of the implementation of the law governing audio-visual activities offered CRTV the opportunity to initiate a project not only to acquire certain Brazilian productions, but also to initiate co-production projects whose first output is the shooting of a movie on works of renown Cameroonian writers, that would appeal to audiences in both countries. The increase in production budget should ultimately help the public broadcaster to produce more internally or co-produce works with local stakeholders or to acquire, on the local market the best products in a reinvigorated independent sector. It is the same logic that prevailed in France where a 5\% domestic production 
ceiling was introduced, in order to force the public service channel to purchase its fictions from independent producers, thus encouraging the emergence of an audio-visual production sector with 2300 producers, totalling an annual turnover of about 2.4 billion Euro (Wojciak, 2015).

\section{Conclusions}

The impact of technological innovation on public television, a major element in the dissemination and preservation of cultural values and a tool to produce meaning and consolidate the foundation of the society on its core values constituted the framework of this study. Its main interest lies, firstly, on the confrontation of this sociological phenomenon, television to the emergence of technological innovation as the latter deeply impacts both on its morphological configuration, its social mission and its functioning, through the internal practices of its techno-structure and, secondly, in observing how this change from an international decision was integrated into the national political agenda and triggered upheavals in both the government strategy of organizing the national audio-visual media landscape and in the specific management of public television. The State, as the guarantor of minimum social fabric that holds society around values conveyed through public television and because the public service missions conferred on the national television, is caught in the quest of balance between capital owners, anxious to make profit from their investments (through advertisement and value-added services) and the need to preserve the general interest.

The review of technological innovation interaction-audio-visual public service has revealed technological, economic, political and strategy indicators that organise public action around the national audio-visual policy. More specifically, the public service mission in this new context is bound to reform, technological developments and, particularly, DTT, making it increasingly fragile, torn between cultural obligations as generally understood, even political (satisfying all categories of viewers and covering the whole country) as imposed by the State shareholder and the economic necessities which oblige it to be realistic by playing with the basically commercial logic of the race for the audience. This, all the more, as structural dangers are impacting on it, including the obsolete nature of the technical tool and the ageing of its technical staff, the stagnant nature and low value of its programme schedule, or the transfer of its audience, etc. Nevertheless, the transformation of its very nature prepares it to better face the challenges of the digital environment, since it is gaining more resonance by extending its transmission power and territorial coverage and its ability to diversify its service offer now available on new terminals (computers, mobile phones, etc.), suddenly changing the mode and place of watching television.

The dependence of public television on audio-visual tax is thereby also reduced due to new resources provided for in a legal and regulatory framework established by the new services of the audio-visual sector. Advantages derived from the new organisational and institutional framework, by anticipating the 
profound change of the current configuration of the public television, extends to the establishing of new operators by specialising production, broadcasting and multiplexing. A real challenge for a corporation with of course, a strong technical staff, but ageing and poorly assigned across all its centres and where there is a need to renew and provide them with skills compatible with DTT technology. We should have in mind that the artistic staff is more than ever before required to compete with local and international channels having as core concern the knotty issue of contents, a real Achilles heel of the national audio-visual, less appreciated by Cameroonians, underfunded and deeply unbalanced to the advantage of flow programmes, stock programmes being chiefly foreign.

Ultimately, it seems that technological innovation because of its impact on the lives of citizens taken as a whole (the uses of television are varied) is necessarily accompanied by far reaching ramifications on national public policies and on the sector directly concerned in an effort to master the tool. In the case of Cameroon, digital switch-over has compelled policy-makers to develop a comprehensive strategy, including objectives and decisions aimed at markedly reshaping the national audio-visual landscape at the legal, institutional, infrastructural, economic and cultural levels, and especially, the public television in its structure, functioning and missions. The objective is to get the best from innovation and avoid the adverse effects of lack of preparation and foresight.

\section{References}

Althusser, L. (1976). Positions (1964-1975). Paris : Les Éditions sociales.

Analysys Mason/FTPA/Osiris Intelligence Stratégique (2014). Accompagnement du gouvernement camerounais dans le projet CAM-DTV en vue de la migration de la radiodiffusion analogique à la radiodiffusion numérique. Missions 1, 2, 3, 4. Yaoundé.

Balle, F. (2007). L'avenir de la télévision publique est dans l'audace. La Revue civique. http://www.revuecivique.eu/articles-et-entretiens

Bandolo, H. (1977). La radiodiffusion du Cameroun, problèmes d'efficacité fonctionnelle. Paris: IFP.

Bilé, O. (2015). Les télévisions africaines face aux défis de la modernité. Yaoundé: Ed. l'Harmattan. Yaoundé.

Boussaguet, L., Jacquot, S., \& Ravinet, P. (2010). Dictionnaire des politiques publiques. Paris: Presses de la Fondation Nationale des Sciences Politiques.

Cameroon Digital Broadcasting Switchover (CAM-DBS) (2012). Stratégie camerounaise de migration de la radiodiffusion analogique au numérique. Yaoundé.

Cameroon Digital Brodcasting Switchover (CAM-DBS) (2011). Etat des lieux de l'audiovisuel au Cameroun. Yaoundé.

Campet, J., Cavada, J.-M., \& Elkabach, J.-P. (1994). L'avenir de la télévision publique: Rapport au ministre de la communication. Paris, Ed. La documentation Française.

Charon, J.-M. (2011). Les médias à l'ère numérique. Les Cahiers du journalisme, 22/23, 15-26.

Dioh, T. (2009). Histoire de la télévision en Afrique noire francophone des origines à nos jours. Paris: Ed. Khartala.

Maigret, E. (2007). Sociologie de la communication et des médias. Paris: Armand Colin. 
Mattelart, T. (2015). L’Afrique subsaharienne au défi des médias internationaux. http://www.inaglobal.fr/television/article/lafrique-subsaharienne-au-defi-des-medias-i nternationaux-8325

Minlo, R. S. (2013). Cameroun Radio Television, un grand malade ? Diagnostic fonctionnel de l'audiovisuel public. Yaoundé: l'Harmattan Cameroun.

Muller, P. (2011). Les Politiques publiques. Paris: PUF.

Rapport du Comité ad hoc des experts nationaux pour la restructuration institutionnelle et opérationnelle de la CRTV, 2012.

Wojciak, T. (2015). Delphine Ernotte Cunci plaide pour une évolution des règles de production. http://www.cbnews.fr/medias/

Submit or recommend next manuscript to SCIRP and we will provide best service for you:

Accepting pre-submission inquiries through Email, Facebook, LinkedIn, Twitter, etc. A wide selection of journals (inclusive of 9 subjects, more than 200 journals)

Providing 24-hour high-quality service

User-friendly online submission system

Fair and swift peer-review system

Efficient typesetting and proofreading procedure

Display of the result of downloads and visits, as well as the number of cited articles

Maximum dissemination of your research work

Submit your manuscript at: http://papersubmission.scirp.org/

Or contact ajc@scirp.org 